\title{
Factors That Influence Effective Strategic Planning Process In Organizations
}

\author{
Job Kipkemboi Kiptoo, Dr. Fred Mugambi Mwirigi, \\ ${ }^{1,2}$ Jomo Kenyatta University of Agriculture and Technology. \\ P.O. BOX 81310 - 80100, Mombasa, Kenya
}

\begin{abstract}
The general objective of this study was to identify factors that influence effective strategic planning process in organizations. It looks closely at the key factors that influence strategic planning and why organizations have to plan for the future for them to remain relevant in the market. This will be achieved by aligning strategic plan with the vision and mission of the organization.

The study explores the connection between strategic plans with organization structure, organizational culture, leadership and human resources. This paper specifically analyses the factors that influence strategic planning and recommendations that can be employed in order to have a successful implementations of strategic planning in the organizations. The recommendations will also address the gaps that have been identified in this paper.
\end{abstract}

Keywords:- Strategic planning, organization structure, organizational culture, human resource

\section{INTRODUCTION}

A strategic plan is a set of processes undertaken in order to develop a range of strategies that will contribute to achieving the organizational direction (Tapinos et al...2005). Therefore, this clearly indicates that companies have to arise to the occasion that they have to develop strategies that will drive the organization in achieving the set goals and objectives as per the vision and mission of the organization. By doing so then the organization will have to formulate strategies that will guide to the direction and the future of where they want to be as an organization. All organizations have a dream to achieve and in doing so they have to have strategies that will propel them to the destination. Strategies can be formulated in three levels that is: corporate, business, and functional level. At corporate level strategies are formulated by the top management or the board of directors (Yabs, 2010). At business level strategies are formulated by middle level managers for example, marketing managers, human resources, production managers, logistics managers among others (Yabs, 2010). Strategy formulation at functional level is done by first line managers or supervisors (Sababu, 2007)

In organization, the Board of Directors are responsible for the long term decision and corporate strategies that should be implemented by the management in order to achieve company's objectives. The Managing Director is expected to lead the management team in ensuring that the corporate strategies are implemented to the latter. The Board is responsible to the shareholders hence giving direction to the management team in order to ensure that the shareholders get return on their investments. The senior top management are expected to ensure that the strategic plans that the board has approved is supposed to be implemented. This means that the management is expected to offer leadership and guidance's on the direction the company should take while undertaking the process of strategic plan. This plays key role in formulation of strategic plans in the organization. For organization to succeed in strategy formulation, it's important for organization to analyse its environment in which they operate by using tools such as the Swot analysis, Pestel analysis, the Porters five forces model, competitor analysis and gap analysis among others (Aldehayyat, Al Khatab and Anchor, 2011)

The Swot analysis is a very powerful tool that helps organizations to address issues relating to strength, weaknesses, opportunities and threats within the organization. If this tool is used, it will helps researchers to understand how the organization can use its strength to take advantages of the opportunities and how organization can use strengths to overcome the threats that the organization is likely to face. Swot analysis is tool that can be used by organization in order to plan how to overcome the several identified weakness and take advantages of the opportunities. This also helps the organization in minimizing the weakness over the threats.

Pestel factors is another tool that organizations uses when formulating strategies because it helps the organization to identify the impact and effects of politics, economic, social, technology, environment and legal aspects on its operations. This will help the organization management team to act appropriately on issues that requires to be addressed especially when the environment in which they operate in is very hostile. Failure to use this tool and respond appropriately after analysis of the organization operations and its environment, it will be 
difficult to respond appropriately to the needs of the customers and other stakeholders. This may impact on the performance of the organization. Because of this, the organization will become irrelevant, making the company to have negative image. This will be evident by the low number of the customers that the organization will be able to attract or acquire hence impacting negatively on the customer service of the organization.

Once the environment has been analysed using the appropriate tools, the organization management is able to come up with the organization vision, mission and organizational values that will drive the organization achieving its objectives. Its important for organization to understand that strategic plan is a process and must be undertaken to its logical conclusion. This means that the logical conclusion will be the actual implementation and the monitoring and evaluation of the entire strategic plan.

\section{OBJECTIVE}

The general objective of the research is to investigate factors that influence strategic planning in an organization. The specific objective of the research will be as follows,

1. To investigate how organization structure affect the strategic planning in an organization

2. To establish how leadership affect strategic planning in an organization

3. To investigate whether organization culture influence strategic planning in an organization.

4. To establish how human resource influence strategic planning in an organization

\section{LITERATURE REVIEW}

Many scholars agree that a strategic plan needs to be simple, realistic and neither too ambitious nor insufficiently demanding (Leggate and Thomas, 1977; Aldehyyat et al., 2011). It should allow some degree of flexibility to fit with the changing environment. Mintzberg, 1994 adds another perspective by highlighting the danger of planning in that it assumes the world will stop while managers wait to plan and implement strategies. This clearly demonstrates why strategic plans should be made in such a way that it is flexible to accommodate environmental changes and other effects that can influence the prevailing situation.

Most organizations in the current trend are converging in big and luxury hotels in order to come up with the most appropriate strategic plans that suit the organizations. In today's world, most of management teams or managers of organization, profit and non-profit organizations spend considerable time, energy and money for formulating and assigning basic strategies of their organizations. However the biggest problem is the implementation of the strategies that are able to elaborate clearly the company's vision but the employees have a different perception of that, this may have negative effective in achieving company's objective that are derived from the vision. This means that the management must be prepared to ensure that all the employees in the organization understand the importance of strategic plan.

\subsection{ORGANIZATIONAL STRUCTURE}

Every organization has a unique structure that reflects its current image, reporting relationship and internal politics. Okumus (2003:876) defines "organizational structure" as "the shape; division of labour; job duties and responsibilities; the distribution of power, and decision-making procedures within the company". Louw and Venter (2006:406) suggest the following definition: "The formal pattern of interactions and coordination designed by management to link the tasks and patterns of individuals and groups in achieving organizational goals". Okumus (2003) cautions that issues for consideration must include: the impact of a new strategy on potential changes in duties; roles; decision making; and on reporting relationships. Leaders must consider whether the organizational structure facilitates the free flow of information; co-ordination, and the cooperation between management and other functional areas. Simplistically, structure informs "who does what", and "levels of accountability". This clearly shows that organizational structure is a fundamental factor when looking at how strategic planning can be implemented in organizations. Without proper structures then strategic planning might not see the light in some organization because structures play a major roles in delivering the expected results.

Chandler, 1962 considered the contingency relationship between a firm's corporate strategy and its internal administrative structure. The ensuing debate on the contingent relationship between strategy, structure, and firm performance flourished in the 1970's and 1980's. It has subsequently been revived through a closer empirical examination of dynamics and causality and calls for an extension of the analysis to various forms of strategy and structure that had not previously been considered. The literature on the theory of organizations has extensively studied the way the organizational structure affects the behaviour of the members of the organization due to the fact that structures can easily influence the outcomes in various institutions. However, very little empirical evidence exists on what part of the organizational structure matters and what is its main channel of influence exits in organization. Different structures that exits in organizations impact differently on 
the overall performances of the company. When addressing the organizational structures in organization, it important to look at the vertical chains.

The vertical chain defines the level of bureaucracy within the organization and the way the business is managed by the management. This indicates that one will have to look at the processes and procedures within the organization to the latter. A vertical structure creates a chain of command that relates the headquarters to the lowest level business units, through a series of intermediate layers that take care of executing headquarters directives at a more disaggregated level. The allocation of authority and tasks to the managers of the intermediate layers in the organization affects both the incentive of the managers as well as the ability of the headquarters to monitor them because each manager is responsible for his activities within the organization. Vertical structures are important in areas such as production facilities or factories where efficiency and standardized processes are of the utmost importance. At the same time, the degree of specialization matters because most of the management team will be placed at the right position within the structures hence making the position holders to prove their expertise on the job. This means that different specialities will be placed to perform on areas that are trained and have experience that match the job that exit in the organization.

Its common knowledge that members in various organizations have different and special competences affects the incentives within the vertical chain of the organization. For example, the fact that managers share the same qualifications improves the "congruence" (Dessein, 2002). This should be reflected in higher delegation and ameliorated coordination. The lower informational asymmetry may help the decision-making process and help to generate more information and provide more expertise. However, different qualifications may make it more difficult to reach coordination because each team may concentrate on their core competences without relating to the head office hence having a serious impact on the organization. It's important that all departments in an organizations works together for the success of the institution because any disagreements may results to disintegration within its functions.

Any operating organization should have its own structure in order to operate efficiently with the aim of achieving the set targets in the organization. In any organization, the organizational structure is of critical importance for the business to succeed because all the functions will be aligned to the business. This means that the organizational structures will clearly demonstrates the character of an organization and the values that it's uphold in the industry or sector. Therefore, when doing business with an organization or getting into a new job in an organization, it is always a great idea to get to know and understand their organizational structure so that one can be a breast to the organization structure. This will help one too see the true picture of the organization at a glance. In summary we can say that organizational structure determines how roles, powers, responsibilities, and controls are coordinated within the different levels of management. This will entirely depend on the organizations objectives and the strategies that the organization envisaged to use in delivery the expected results.

However, in a decentralized structure we find that decision making power is vested on various departmental heads with different degrees of independences in terms of processes, procedures, and implementation of various tasks and activities whereas in a centralized structure, the top management controls all the decision making and has all the powers over the departments. Therefore, arising from the above, this indicates that organizational structures actually contribute to the success of strategic planning in an organization. The reason is that the structures should be able to support the strategic planning considering that the same structures are supposed to implement and monitor and evaluate the performance of the organization.

\subsection{ORGANIZATIONAL CULTURE}

Organizational culture is the behaviour of human beings who are part of an organization and are attached to the actions that they perform within the organization. This includes organizational values, vision, symbols, beliefs, norms, habits etc, and these are pattern of beliefs and assumptions that an organization as developed for a period of time and that are taught to new employees who are joining the organization as a way of pursuing, thinking and feeling about the organization. In summary we can say that organization culture is a set of shared mental assumptions within people in an organization that guides interpretation and actions in an organization by defining appropriate behaviour or actions within the organization. Most organizations have its own unique culture which can be reflected in its mission, vision, core values, and adoptability in the environment in which they operate in.

Organizational culture is an idea in the field of organizational studies management which describes the psychology, attitudes, experiences, beliefs and values (personal and cultural values) of an organization (Schein,2009). It has been defined as the specific collection of values and norms that are shared by people and 
groups in an organization and that control the way they interact with each other and with stakeholders outside the organization (Deal \& Kennedy, 2000). From organizational values, we can develop organizational norms, guidelines, or expectations that prescribe appropriate kinds of behaviour by employees in particular situations and control the behaviour of organizational members towards one another hence making the organization to have a common status for identification.

Corporations are organizations and are also legal entities, Schein (2009); Deal and Kennedy (2000); Kotler, Armstrong, Saunders and Wong (2002) state that organizations often have very differing cultures as well as subcultures. The organization culture influences the choice of strategy and therefore, organization has particular values and beliefs that all employees are supposed to observe. The culture may vary from one organization to the other depending on how it has been align to the vision. The cultures influence the day to day operations of the organization and may influence what is acceptable or unacceptable in the organization depending on the environment on which the organization operates. This means that if the organizations are implementing strategic plan, it's important that everyone is brought on board so that everyone can own the process. Cultures in an organization contribute a lot in implementing the strategic plan and without involving all the members of staff, and then outcome might be very unpromising. Culture has long been on the agenda of management theorists and culture change must mean changing the corporate ethos, the images and values that inform action and the new way of understanding organizational life must be brought into the management process. Deal and Kennedy (1982) argue that culture is the single most important factor accounting for success or failure in organizations. They identified four key dimensions of culture;

a) Values - the beliefs that lie at the heart of the corporate culture.

b) Heroes - the people who embody values.

c) Rites and rituals - routines of interaction that have strong symbolic qualities.

d) The culture network - the informal communication system or hidden hierarchy of power in the organization.

Peters and Waterman (1982) suggest a psychological theory of the link between organizational culture and business performance. Culture can be looked upon as a reward of work; we sacrifice much to the organization and culture is a form of return on effort.

Kanter (1989) refers to the paradox implicit in linking culture with change. On the surface, culture has an essentially traditional and stable quality, so how can you have a 'culture of change?' Yet this is exactly what the innovative organization needs.

The literature of organizational culture is as relevant to public science management as it's to the management of private sector business organizations. With the rapidly changing environment and the continuing insights into organizational effectiveness, most organizations are seriously rethinking what they can do and how best they can define and accomplish their goals and objectives. In doing so, this will help them to define the organization culture in order to achieve the set targets.

In order for organizations to succeed in strategic planning it's evidently important that the organizational culture plays a major role and the top management should be able to embrace culture change within the organization. This can only happen if the entire management and the employees believe that culture is essential for both successful organizational culture and maximizing the value of human capital.

\subsection{LEADERSHIP}

Leadership is a process by which a person influences others to accomplish an objective and directs the organization in a way that makes it more cohesive and coherent. Leaders carry out this process by applying their leadership attributes, such as beliefs, values, ethics, character, knowledge, and skills in order to guide and drives the organization. It's important to note that leaders are expected to be mentors who can be dependent on by the people that one is leading. This means that the leader should be able to exercise skills so that the people will be able to appreciate his leadership skills. In management there is difference between a leader and a manager because the latter wants to maintain the status quo whereas a leader will always question the existing position. Therefore it's important to note that leadership in any organization will always affect the strategic planning in organization if proper leadership does not exist.

Leadership differs in that it makes the followers want to achieve high goals, rather than simply commanding people around without showing leadership skills that can be emulated by others. It's important to note that poor leadership will influence strategic planning in the sense that leaders can apply different leadership styles or skills which can have positive or negative effect on the organization. In this regard, leaders should be 
able to offer leadership that can take organization to great heights by giving guidance and direction. 'Just as old world explorers navigated uncharted waters, today executives have the challenge of leading organizations into new unmapped outposts of the global market place" Gregerson, Morrison and Black. From the above, we can explain that leadership skills and styles affect the strategic plan of an organization in the sense that each firm is able to employ unique skills of different strategic leaders to successful lead and manage envisaged organizational changes. While there is no paucity of information related to the phenomenon of leadership, the concept of an effective strategic leader is nebulous and still requires much investigation. Goleman (2001) corroborates this by suggesting that strategic leadership will never be an exact science.

Arising from the above, we can say that leadership plays a major role in implementing strategic plan in an organization because leaders must be able to show commitment and dedication for any meaningful event to take place.

\subsection{HUMAN RESOURCE}

Most organizations view the department of human resources as an administrative function within the organization but they forget that the department has a big opportunity to align it with its strategic plans. In the event that the human resource is included in the strategy of an organization, its alignment may not go beyond a forecasting function. The main reason is that human resource is not aligned with the strategy of an organization and in most cases the department does not participate in the strategic planning considering that most of the strategic planning meeting are associated with revenue generating areas whereas the human resources is associated as a support team. Also another reason where the human resource is always left out of the strategy planning is that by its nature, human resource is about people, which is the core of an organization and its strategic plan.

The hypothesis is that it is hard to measure human resource success and thus it is considered a soft and not important in the strategy development because one cannot measure its performance in terms of financials. However, human resource is often viewed as a tool that is supposed to provide labour force to the organization and should be able to ensure that discipline is maintained at all levels within the organization. Any deviation from this function will mean that the department is not performing as per the expectation. It's important that the human resource department should be able to ensure that the employees' benefits are properly administered as per the prevailing laws of the country. In contrast to the human resource administrative function, strategic human resource practices are more contemporary concepts. Consequently, organizations are less likely to expect these practices to have an impact on bottom line business results (Huselid, Jackson, \& Schuler, 1997). A definition of strategic human resource management is the design and implementation of a set of internally consistent practices that ensure an organization's human capital contributes to the achievement of its business objectives (Huselid, Jackson, \& Schuler, 1997).

In the corporate world, the essence of human resource is strategic and when properly aligned, it contributes to a successful strategy and the financial bottom line. This means that human resource needs to maintain a strong administrative foundation and use this respect in championing for participating in strategic planning meeting. Such move will ultimately propel human resources to the position whereby it can actually facilitate strategic planning in organization hence giving value to the organization. This can easily make the department to be a game changer by providing value that can influence the performance of the organization.

Nevertheless, when the shortcomings of human resource are addressed then the department will be able to position itself as a strategic unit that the organization can rely on especially during monitoring and evaluation of strategic planning. The human resource is viewed as the people department that provide labour to the organization. The organization ultimately determines the effectiveness of strategy development, implementation, and subsequent competitive success. A strategic approach that is aligned with human resource ensures that an organization's employees, skills, and abilities contribute to the achievement of its business goals (Huselid, Jackson, \& Schuler, 1997).

In general, the strategic human resource management is the process of linking the human resource function with the strategic objectives of the organization in order to improve performance. Organizations are increasingly looking at human resources as a unique asset that can provide sustained competitive advantage. The changes in the business environment with increasing globalization, changing demographics of the workforce, increased focus on profitability through growth, technology changes, intellectual capital and never ending changes that organizations are undergoing have led to increased importance of managing human resources (Devann, Fombrum and Tichv.1981;Wright .1998). In this scenario, a human resource department that is highly 
administrative and lacks strategic integration fails to provide the competitive advantage needed for survival, thus losing its relevance in any sector of business.

Huselid and Becker (1997) founded that there were noticeable financial returns for the organizations whose human resource management systems have achieved operational excellence and are aligned with business strategic goals. According to Ulrich (1998), one of the roles of human resource is to become strategic business partner. Youndt and Snell (1996), finds that firms employing human resource practices according to the stated strategy are regarded to have better perceptual performance. This therefore summarizes that human resource contribute a lot to the success of strategic planning in an organization and if not implemented well then the outcomes will be felt within the organization.

\section{RESEARCH METHODOLODY}

The research methodology used in this paper is desktop study which refers to seeking facts, general information on a topic, historical background, study results, etc. that has been published or exists in public documents.

\section{CONCLUSION}

From the above research study it's evident that organization structures affect strategic planning in an organization if proper measures are not put in place to ensure that all employees in the organization are involved from the onset. Also in order for the employees to participant fully in the strategic planning the organization should encourage down upward communication whereby the employees will feel that the organization consider them as part of the success in the strategic planning of the organization.

Strategic management involves formulation and implementation of strategies that can drive organizations to greater heights. This means that the top management has to choose strategies or strategy that is most appropriate to remain relevant and competitive in the turbulent environment. The strategic choice is influenced by various factors that prevail at that particular time hence it's important for organizations to be well prepared. These are the contingent factors that determine the kind of strategy that is selected for implementation to achieve particular objectives that the organization has planned to achieve. These factors include firm level factors and industry factors. The firm level factors include resources, structure, organization culture, chief executive officer attributes and board characteristics. Basically these are factors that are within the organization and in most cases the organization has control over them. The strategy choice is influenced by the business environment in which the business operate and organizations should be able to scan the environment critical to avoid other challenges that may arise. These factors are normally beyond the organization because there are external hence difficult to be managed by the organization. The strategy links the organization to the environment and the strategy chosen in turn has an effect on the performance of an organization. The performance may vary from one strategy to another and also depending on the measure of performance used by the organization or the business. The tools used in measuring the performance are very critical when addressing the success factors for implementation.

Leadership in an organization is the cornerstone of success whereby the leadership should be able to chart the destined of the organization by using the vision, mission and the goals of the organization in order to achieve the set objectives. If leadership fails then strategic planning will not succeed hence affecting the strategic planning of the organization. This means that the success of any strategic plan is pegged on the leadership of the organization and especially the lead team that is driving the activities that are related in the implementation.

Organizational culture can serious influence the strategic planning in an organization if the employees and the management don't have a positive mind-set on what the company needs to achieve. This means that the organizational culture should be cascaded to all the staff in the organization so that everyone within the organization understands the importance and to ensure that they own the process of success.

Finally human resources in an organization contribute the biggest percentage in the success of any strategic planning because they are the key drivers. Actually the human resource is the driving force in any firm hence all employees and management must have an integration process for ensuring that strategic planning is not frustrated by an individual for the success of the process. In most cases, all strategic planning that have failed to take off is due to lack of commitment and dedication of human resource or human capital within the organization. 
Aligning human resource and strategic plans is an important endeavour for every organization. Studies strongly support the alignment between strategies, human resource and performance and thus show the potential role human resource can play in implementing strategy and developing an organization's competitive advantage Wright, Smart, McMahan, 1995. The alignment between human resource activities and strategy planning can be formed by human resource which also needs to expand beyond an administrative function and focus more on how it can support the organization in strategic planning and implementation.

By increasing the competencies of human resource, the department will increase its creditability and be integrated into a strategic role within the organization set up. When human resource measures itself from a business perspective and by the value it brings an organization, top management will not ignore human resource in the strategy process. Instead, top management will welcome human resource input because it will have a clear understanding of how human resource affects the bottom line from a business and or strategic plan. In the current environment, human resource managers are trained to be the focal point in organizations and in most cases they are the drivers of strategic planning in organizations. This means that human resource is an integral part for the success of implementing strategic planning in any organization.

\section{RECOMMENDATION}

The purpose of strategic planning is to set overall goals for the business and to develop a plan to achieve. This means that one needs to understand the business and set out the priorities that need to be undertaken. Any decision taken in growing the business means embracing the risks that come with growth hence one should be prepared for the outcome of the results. Spending time on identifying exactly where you want to take the business and how you will get there should help to reduce and manage the risks that is involved in the project that one undertake to do.

As the business becomes larger and more complex, so strategy formulation will need to become more sophisticated, both to sustain growth and help to master the game in the business. Leadership and resources are needed to keep the business developing in order to ensure that it remains relevant. To do this, one will also need to start collecting and analysing a wider range of information about the business, both about how it operates internally and about how conditions are developing in the current and potential markets.

The process of strategic planning is about determining the direction in which one want to take the business. It involves setting out the overall goals for the business. By contrast, the purpose of the business plan is to provide the detailed roadmap that will take the desired direction. Strategic planning and business planning should be complementary, but effective strategy development requires to shift the focus from the day-to-day concerns of the business and to consider the broader and longer-term options that will see the business grow to greater heights. Strategic planning is about positioning the business as effectively as possible in the marketplace so that competitors can be made irrelevant.

Effective strategic planning involves considering options that challenge the way that business has been done. It may be the decision-making in some areas which will be handed to others, or that processes which have worked well in the past will no longer fit with future plans considering the dynamics in various businesses. This means that various businesses will have different strategic planning options in order to achieve the set objectives of the business.

The key to implementation of the objectives identified in the strategic planning is to assign goals and responsibilities with budgets and deadlines to responsible managers and supervisors, for example, key employees or departmental heads. Monitoring the progress of the implementation plan and reviewing the strategic plan against implementation will be an on-going process. Monitoring implementation is the key to the success of strategic planning in any organization. Using key performance indicators (KPI's) and setting targets and deadlines is a good way of controlling the process of introducing strategic changes.

Strategic planning can involve making both organizational and cultural changes to the way the business operates. The three major keys to successful strategic planning and implementation are commitment, credibility, and communication. The leaders must show commitments which include an adherence to the full and thorough process of strategic planning as indicated in the document that is used as the guiding document.

Credibility is created and maintained by following three guidelines namely; representative participation, adherence to the complete process, and clear documentation. The organization should have strategic planning committee which should have representatives from all areas of the organization and adhere to the steps of the process. The main aim of involving each department is to ensure that there is ownership of the document from the onset. The committee should document all of its research and activities to serve as the basis for the strategic plan and its background materials. It will also serve as a clear record of the committee's activities open for all to see and evaluate. The strategic planning should be open to all for review and input by all the concern parties so that everyone can own the process. This will help in the actual implementation because all the concerns parties were involved from the beginning to the end. Also the review can be done in a manner that all parties concerned are encouraged to participate in the entire process. 
The principles and goals of strategic planning are important and should be explained to every member of staff within the organizations so that they can have an input and evaluate the recommendations given out by the committees mandated by the organization. Any additional aid to implement the strategic plan is to create an integrated system by which the strategic plan becomes the benchmark for progress in an organization and becomes a system of accountability to all the concern persons in the organization.

Therefore, strategic planning is the key to assuring that organizations are prepared for the challenges of today, tomorrow and the future being guided by the vision, mission and goals of the organization in order to achieve the set objectives. This is the ultimate decision for all organizations that wants to be the market leaders in the industry in which they operate.

\section{REFERENCE}

[1]. Aldehyyat, J., Al Khattab, A. and Anchor, J. (2011), The use of strategic planning tools and techniques in hotels in Jordan. Management Research News, 34 (4): 43-60.

[2]. Chandler Jr., A. D. (1962): Strategy and structure: Chapters in the history of the American industrial enterprise. Cambridge, MA: MIT Press.

[3]. Deal E.T and Kennedy A.A (2000), corporate culture, Persons Cambridge MA.

[4]. Devanna, M.A., Fombrun, C. \& Tichy, N. 1981, Human resource management: A strategic perspective. Organizational Dynamics, 9 (3): 51-68.

[5]. Goleman, D. 1998. "What makes a leader?” Harvard Business Review, November-December: 93-102.

[6]. Goleman, D. 2000. "Leadership that gets results", Harvard Business Review, March- April: 78-90.

[7]. Gregerson, H.B., Morrison, A.J. and Black, J.S. 1998. "Developing leaders for the global frontier", Sloan Management Review, 40(1):21-32.

[8]. Huselid M.A and Becker, B.E.1997, The impact of high performance work system, implementation effectiveness, and alignment with strategy on shareholders wealth. Academy of Management proceedings, 144-149

[9]. Huselid, M, Jackson, S, \& Schuler, R. 1997. Technical and Strategic Human Resource Management Effectiveness as Determinants of Firm Performance, Academy of Management Journal, Vol. 40, No. 1, 171-188

[10]. Kotler P, Armstrong G,Saunders J, and Wong, V (2002). Principles of marketing $3^{\text {rd }}$ FT/ Prentice Hall

[11]. Leggate, P. and Thompson, J., (1997). The management of development planning in international schools, International Journal of Educational Management, 11(6): 268- 273.

[12]. Louw, L. and Venter, P. 2006. Strategic Management: Winning in the Southern African workplace. Cape Town: Oxford University Press.

[13]. Mintzberg, H. (1994). The fall and rise of strategic planning, London: Prentice Hall.

[14]. Sababu, B. (2007). Strategic Management: The Analytical Approach. Nairobi: Jomo Kenyatta Foundation.

[15]. Schein E.H (2009), Organization psychology, Prentice Hall.

[16]. Schuler, R.S. 1992. Strategic human resource management: Linking the people with the strategic needs of the business. Organizational Dynamics, 21 (1): 18-33.

[17]. Schuler, R. S. \& Jackson, S. E. 1987, Linking competitive strategies with human resource management practices. Academy of Management Executive, 1 (3): 207-219.

[18]. Schuler, R. S., \& Jackson, S. E. 1987, Organizational strategy and organizational level as determinants of human resources management practices. Human Resources Planning, 10 (3): 125-143.

[19]. Schuler, R.S. \& Walker, and J.W. 1990, Human resources strategy: Focusing on issues and actions. Organizational Dynamics, 19 (1): 4-20.

[20]. Tapinos, E,Dyson, R and Meadows, M, (2005). The impact of performance measurement in strategic planning, International Journal of productivity and performance management, 54 (5/6):370-384

[21]. Ulrich, D. 2000. How the Human Resource Function Can Create Value and Drive Strategic Success. Harvard Business School, Balanced Scorecard, 2000

[22]. Ulrich, D. 1998. A New Mandate for Human Resources, Harvard Business Review, January - February, 1998

[23]. Wright P, Smart, D, and McMahan, G, 1995, Matches between human resources and strategy among NCCA Basket Teams, Academy of Management Journal, Vol. 38, No 4, 10521074

[24]. Wright, P.M. \& McMahan, G.C. 1992, Theoretical perspectives for strategic human resource management. Journal of Management, 18 (2): 295-320.

[25]. Wright, P.M. 1998. Introduction: Strategic human resource management research in the 21stcentury. Human Resource Management Review, 8 (3): 187-152.

[26]. Yabs, J. (2010). Strategic Management Practices $2^{\text {nd }}$ edition. Nairobi: Lelax Global (K) Ltd

[27]. Youndt, M. A. \& Scott, S.A. 1996. Human resource management, manufacturing strategy, and firm performance, Academy of Management Journal, 39 (4): 836-857. 